\title{
Biologi Portunus pelagicus, Linnaeus, 1758 (Malacostraca : Portunidae) dari Perairan Jepara Ditinjau dari Distribusi Ukuran, Tingkat Kematangan Gonad, dan Pertumbuhan
}

\author{
Ulfah Nur Hidayah*, Ibnu Partikto, Irwani \\ Departemen IImu Kelautan, Fakultas Perikanan dan IImu Kelautan, Universitas Diponegoro \\ JI. Prof. H. Soedarto S.H, Tembalang,Semarang, Jawa Tengah 50275 Indonesia \\ ${ }^{*}$ Corresponding author, e-mail: yayaunh26@gmail.com
}

\begin{abstract}
ABSTRAK : Rajungan (Portunus pelagicus) merupakan salah satu komoditi perikanan yang memiliki nilai ekonomis tinggi yaitu Rp. $70.000-90.000 / \mathrm{kg}$ dan banyak diminati oleh masyarakat baik di dalam maupun luar negeri. Penurunan potensi sumberdaya rajungan (Portunus pelagicus) di beberapa perairan Indonesia mulai memprihatinkan. Hal tersebut dapat dihindari dengan memahami faktor-faktor internal dan eksternal yang berpengaruh pada sumberdaya rajungan. Penelitian ini bertujuan untuk mengetahui distribusi ukuran, nisbah kelamin dan tingkat kematangan gonad, hubungan panjang berat dan faktor kondisi, serta tingkat pertumbuhan rajungan berdasarkan fase bulan baru dan bulan purnama di Perairan Teluk Awur Jepara. Hasil penelitian distribusi ukuran lebar rajungan rata-rata 12,65 $\pm 1,335$ pada bulan purnama dan 12,64 $\pm 1,259 \mathrm{~cm}$ pada bulan baru. Distribusi berat rata-rata 147,28 $\pm 53,85$ gram pada bulan purnama dan 146,65 $\pm 53,31$ gram pada bulan baru. Distribusi tingkat kematangan gonad rajungan betina yaitu TKG 1 sebanyak 126 ekor, TKG 2 sebanyak 77 ekor, dan TKG 3 sebanyak 112 ekor sedangkan rajungan betina yang belum matang gonad 225 ekor. Nisbah kelamin rajungan jantan dan betina di Teluk Awur yaitu 0,9:1. Pola pertumbuhan rajungan di Teluk Awur yaitu bersifat allometrik negatif dimana pertumbuhan panjang karapas lebih dominan daripada pertumbuhan bobot tubuhnya. Sedangkan tingkat pertumbuhan rajungan untuk mencapai panjang maksimal yaitu $8,16 \mathrm{~cm}$ dengan koefisien pertumbuhan 0,6 per tahun.
\end{abstract}

Kata Kunci : Ukuran, Pertumbuhan, Rajungan, Teluk Awur, Tingkat Kematangan Gonad

\section{The Biology of Portunus pelagicus, Linnaeus, 1758 (Malacostraca: Portunidae) from Jepara Waters in terms of Size Distribution, Gonad Maturity Level, and Growth}

\begin{abstract}
Blue Swimming Crab (Portunus pelagicus) is one of the fisheries commodity which has high economic value Rp. $70.000-90.000 / \mathrm{kg}$ and is much in demand by the both domestic and foreign societies. The decrease of blue swimming crab (Portunus pelagicus) resource potential in some Indonesian waters is starting to apprehensive, that can be avoided by understanding the internal and external factors that influence the blue swimming crab resources. This research aimed to determine the size distribution, sex ratio and gonad maturity level, the relationship of length of weight and condition factor, and blue swimming crab growth rates according to the phase of the new moon and full moon in the Jepara Teluk Awur Waters. The results of the research of the width distribution of most crab in the full moon 12,65 $\pm 1,335 \mathrm{~cm}$ and 12,64 $\pm 1,259$ in the new moon. The distribution of weight are 147,28 $\pm 53,85$ grams in the full moon and 146,65 $\pm 53,31$ in the new moon phases. The distribution of maturity levels of female blue swimming crab gonads that is TKG 1 amounted 126 crabs, TKG 2 amounted 77 crabs, and TKG 3 amounted 112 crabs. While the female immature blue swimming crab were gonads 225. The sex ratio of male and female blue swimming crab in Teluk Awur is 0,9:1. The blue swimming crab growth pattern in Teluk Awur is negative allometric where the growth of carapace length is more dominant than the growth of its body weight. While the blue swimming crab growth rate to reach the maximum length is $8.16 \mathrm{~cm}$ with a growth coefficient of 0.6 per year.
\end{abstract}

Keywords: Distribution, Growth, Blue Swimming Crab, Teluk Awur, Gonad Maturity 


\section{PENDAHULUAN}

Pantai Teluk Awur merupakan salah satu pantai di kabupaten Jepara yang dimanfaatkan oleh masyarakat sekitarnya untuk penangkapan ikan, rajungan, budidaya laut, pariwisata, dan pendidikan (Mustofa, 2018). Rajungan (Portunus pelagicus) adalah kepiting laut yang banyak terdapat di perairan Indonesia. Rajungan (Portunus pelagicus) merupakan salah satu komoditi perikanan yang memiliki nilai ekonomis tinggi, banyak diminati oleh masyarakat baik di dalam maupun luar negeri, bahkan untuk memenuhi seluruh kebutuhan ekspor rajungan sebanyak 21,57 ribu ton/tahun atau setara dengan $2,69 \%$ dari total volume ekspor perikanan masih mengandalkan dari hasil tangkapan laut (KKP, 2018).

Menurut KKP (2018), permintaan pasar yang tinggi mencapai 145 ton/tahun atau senilai 44 Miliar Rupiah, telah menyebabkan eksploitasi yang intensif mencapai 29.038 ton senilai US\$ 321.842 terhadap sumber daya rajungan di Indonesia. Berdasarkan data KKP, tercatat nilai ekspor daging rajungan Indonesia pada tahun 2017 menempati posisi ke-3 terbesar setelah Tuna dan Udang dengan nilai US\$ 411 juta.

Menurut Badan Pusat Statistik (2018), potensi rajungan yang tumbuh secara alamiah di laut sangat melimpah sebesar 487.000 ton, namun populasi rajungan di alam semakin terancam karena hasil tangkapan rajungan dari 200.000 ton menjadi 154.442 ton pada tahun 2016, menurut Sunarto et al., (2010) hal ini disebabkan karena rusaknya habitat dan eksploitasi oleh nelayan di beberapa daerah.

Besarnya permintaan ekspor ke beberapa negara menyebabkan beberapa perairan di Indonesia yang termasuk dalam WPPNRI 715 yang meliputi Teluk Tomini, Laut Maluku, Laut Halmahera mengalami overfishing (Badan Pusat Statistik, 2018). Hal tersebut mengakibatkan rendahnya ketersediaan rajungan di alam. Untuk memenuhi permintaan konsumen dengan hanya mengandalkan hasil tangkapan, tidak akan dapat memenuhi permintaan pasar, terutama pasar luar negeri yang terus meningkat 30\%. Disisi lain penangkapan yang hanya mengandalkan ketersediaan di alam menyebabkan potensi laut ini akan cepat punah (Jumaisa et al., 2016).

Penurunan potensi sumberdaya rajungan (Portunus pelagicus) di beberapa perairan Indonesia mulai memprihatinkan hal tersebut dapat dihindari dengan memahami faktor-faktor internal dan eksternal yang berpengaruh pada sumberdaya rajungan. Menurut Mawaluddin (2016), Hasil tangkapan rajungan dipengaruhi oleh faktor eksternal dan internal. Salah satu faktor eksternal yang mempengaruhi adalah faktor fase bulan.

Permasalahan semakin kompleks karena hingga saat ini data distribusi ukuran, tingkat kematangan gonad, dan pertumbuhan rajungan hasil tangkapan berdasarkan fase bulan belum tersedia. Berdasarkan uraian tersebut perlu dilakukan suatu kajian tentang distribusi ukuran, tingkat kematangan gonad, dan tingkat pertumbuhan rajungan berdasarkan fase bulan di perairan Telukawur yang nantinya dapat digunakan sebagai sumber acuan dalam kebijaksanaan pengelolaan rajungan dimasa yang akan datang.

\section{MATERI DAN METODE}

Penentuan lokasi pengukuran parameter lingkungan dilakukan dengan menggunakan Purposive Sampling Method. Penentuan titik pengukuran ini mengacu pada area penangkapan rajungan nelayan yang ada di Teluk Awur. Area penangkapan rajungan dilakukan berdasarkan keberadaan rajungan. Hartoyo (Komunikasi Pribadi, 2018).

Sampel rajungan diambil kurang lebih 150 individu dari hasil tangkapan nelayan pada setiap titik sampling. Hal tersebut untuk memenuhi standar statistik perhitungan. Pengukuran rajungan dilakukan selama 4 bulan yaitu dari bulan Oktober akhir sampai dengan Januari dengan interval 2 minggu sekali sesuai dengan fase bulan purnama dan bulan baru.

Jenis kelamin rajungan dapat dikenali dari ukuran, warna karapas dan bentuk sisi abdomennya. Rajungan betina umumnya memiliki ukuran tubuh yang relatif kecil dibandingkan jantan (Sunarto, 2007). Karapasnya berwarna hijau kecoklatan sedangkan Rajungan jantan memiliki karapas dengan warna dasar biru. Rajungan betina memiliki bentuk penutup abdomen 
yang lebar dengan bentuk menyerupai kubah sedangkan rajungan jantan memiliki bentuk sempit, memanjang dan meruncing pada ujungnya.

Penentuan klasifikasi tingkat kematangan gonad rajungan ditentukan dengan melihat karakteristik morfologi gonad mengacu pada Kunsook et al., (2014). Pengukuran parameter lingkungan meliputi suhu, salinitas, $\mathrm{pH}$, kecerahan, dan kedalaman. Pengukuran dilakukan di 7 titik yang berbeda. Penentuan ini ditentukan oleh nelayan berdasarkan daerah penangkapan rajungan.

Menentukan nilai maksimum dan minimum dari keseluruhan data lebar karapas dan berat rajungan yang didapat dari jumlah total. Menentukan interval kelas. Menghitung frekuensi dan memasukkan frekuensi masing-masing kelas dengan memasukkan lebar dan berat tubuh dari masing-masing rajungan pada interval kelas yang ditentukan. Persamaan dalam menentukan nisbah kelamin rajungan adalah : $\mathrm{Nk}=\mathrm{Nj}: \mathrm{Nb}$, Keterangan $: \mathrm{Nk}=$ Nisbah kelamin; $\mathrm{Nj}=\mathrm{Jumlah}$ rajungan jantan; $\mathrm{Nb}=$ Jumlah rajungan betina.

Hubungan panjang berat digambarkan dalam 2 bentuk, yaitu isometrik dan allometrik, untuk kedua pola berlaku persamaan (Sperre et al., 1996). Perhitungan faktor kondisi (Ponderal Index) berdasarkan pada data panjang dan berat, menurut Rypel and Richter (2008). Perhitungan parameter pertumbuhan rajungan berdasarkan data frekuensi panjang $\left((L \infty), k, t_{0}, t_{\max }\right)$ menggunakan metode Von Bertalanffy dengan Program FISAT II (Portier dan Nurhakim, 1995) .

\section{HASIL DAN PEMBAHASAN}

Distribusi ukuran rajungan terdiri dari sebaran lebar rajungan dan sebaran berat rajungan. Jumlah rajungan yang digunakan dalam penelitian ini adalah 1.050 ekor. Jumlah rajungan jantan selama penelitian sebanyak 510 ekor dan rajungan betina 540 ekor. Kisaran lebar yang diamati berkisar antara 10,01-16,15 cm. Lebar rajungan terendah yaitu 10,01 cm dan tertinggi $16,15 \mathrm{~cm}$.

Ukuran lebar karapas rajungan yang tertangkap berukuran $100 \mathrm{~mm}(10 \mathrm{~cm}) \mathrm{ke}$ atas dengan demikian sudah sesuai dengan Peraturan Menteri Kelautan dan Perikanan Nomor 01/PERMEN$\mathrm{KP} / 2015$. Hasil tangkapan yang berukuran kecil atau kurang dari $100 \mathrm{~mm}(10 \mathrm{~cm})$ dilepas kembali oleh nelayan hal ini dikarenakan adanya kesadaran dari nelayan Hartoyo (Komunikasi Pribadi, 2018). Namun, masih banyak nelayan yang menangkap rajungan dalam kondisi bertelur.

Hasil berat rajungan terendah adalah 56 gram dan tertinggi yaitu 346 gram. Jumlah rajungan yang didapat pada bulan yaitu 600 ekor sedangkan pada bulan baru sebanyak 450 ekor. Berat rata-rata pada fase bulan purnama yaitu 147,28 $\pm 53,85$ gram dan 146,65 $\pm 53,31$ gram pada fase bulan baru. Pada fase bulan baru bobot rajungan menunjukkan bobot yang lebih tinggi dari pada fase bulan purnama meskipun jumlah individu yang diamati lebih banyak bulan purnama. Menurut Irawan (2015), penambahan bobot rajungan diduga disebabkan karena setiap individu mengalami pertumbuhan yang signifikan sehingga mempengaruhi bobot secara keseluruhan bukan karena jumlah individu.

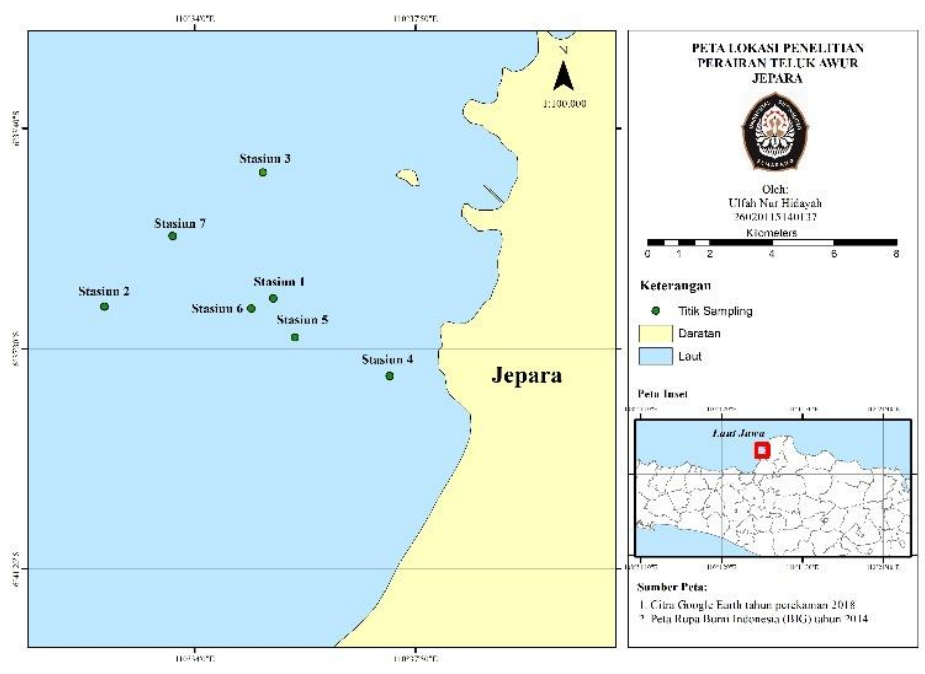

Gambar 1. Peta Lokasi Penelitian 
Selama penelitian pada fase bulan purnama dan bulan baru, jumlah hasil tangkapan rajungan jantan dan betina tertinggi tertangkap pada fase bulan purnama. Hal ini disebabkan data yang diperoleh lebih banyak bulan purnama daripada bulan baru. Hasil tersebut tidak menunjukkan perbedaan hasil tangkapan dalam rentang yang terlalu jauh. Hasil penelitian menunjukkan rasio jantan dan betina rajungan di Teluk Awur dengan perbandingan 0,9:1. Nisbah kelamin idealnya rajungan berkisar 1:1, dibutuhkan 1 rajungan jantan untuk membuahi 1 rajungan betina.

Distribusi Tingkat Kematangan Gonad rajungan yang dianalisa adalah rajungan betina yang tertangkap di perairan Telukawur. Berdasarkan penelitian Tingkat Kematangan Gonad rajungan yang tertangkap yaitu TKG 1 23\% atau berjumlah 126 ekor, TKG 2; 14\% yang berjumlah 77 ekor, TKG 3; $21 \%$ dengan jumlah 112 ekor dan rajungan betina yang belum matang gonad sebanyak 225 ekor atau 42\%. Persentase rajungan betina yang tertangkap di Telukawur yang belum matang gonad relatif lebih tinggi dibandingkan dengan rajungan matang gonad. Banyaknya rajungan betina yang belum matang gonad di perairan Telukawur diduga karena menurut Sukamaran dan Neelakantan (1998), rajungan aktif bertelur pada bulan Januari hingga Februari, sedangkan pada bulan September banyak rajungan betina yang matang gonad. Dan pada bulan Agustus hingga Mei rajungan menetaskan telurnya.

Tabel 1. Distribusi Lebar Rajungan

\begin{tabular}{|c|c|c|c|c|c|c|c|c|c|}
\hline \multirow{3}{*}{ No } & \multirow{3}{*}{ Interval (cm) } & \multirow{3}{*}{ Nilai Tengah } & \multicolumn{7}{|c|}{ Frekuensi Sebaran Lebar Rajungan } \\
\hline & & & \multirow{2}{*}{$\frac{\text { Oktober }}{\text { P1 }}$} & \multicolumn{2}{|c|}{ November } & \multicolumn{2}{|c|}{ Desember } & \multicolumn{2}{|c|}{ Januari } \\
\hline & & & & B1 & P2 & B2 & P3 & B3 & $\mathrm{P} 4$ \\
\hline 1 & $10,01-10,57$ & 10,29 & 10 & 4 & 15 & 9 & 6 & 5 & 3 \\
\hline 2 & $10,57-11,13$ & 10,85 & 28 & 15 & 27 & 14 & 11 & 13 & 7 \\
\hline 3 & $11,13-11,69$ & 11,41 & 9 & 25 & 22 & 20 & 14 & 22 & 17 \\
\hline 4 & $11,69-12,25$ & 11,97 & 18 & 19 & 22 & 22 & 13 & 16 & 22 \\
\hline 5 & $12,25-12,81$ & 12,53 & 14 & 10 & 11 & 21 & 18 & 20 & 23 \\
\hline 6 & $12,81-13,37$ & 13,09 & 19 & 33 & 17 & 30 & 27 & 23 & 31 \\
\hline 7 & $13,37-13,93$ & 13,65 & 24 & 15 & 17 & 22 & 17 & 18 & 22 \\
\hline 8 & $13,93-14,49$ & 14,21 & 18 & 18 & 7 & 7 & 19 & 12 & 14 \\
\hline 9 & $14,49-15,05$ & 14,77 & 9 & 9 & 12 & 5 & 21 & 16 & 9 \\
\hline 10 & $15,05-15,61$ & 15,33 & 1 & 2 & 0 & 0 & 3 & 3 & 0 \\
\hline 11 & $15,61-16,17$ & 15,89 & 0 & 0 & 0 & 0 & 1 & 2 & 2 \\
\hline \multicolumn{3}{|c|}{ Total } & 150 & \multicolumn{2}{|c|}{300} & \multicolumn{2}{|c|}{300} & \multirow{2}{*}{\multicolumn{2}{|c|}{300}} \\
\hline & $10 t a$ & & & & & 1050 & & & \\
\hline
\end{tabular}

Keterangan : P1 = Fase Purnama 1; B1 = Fase Baru 1; P2 = Fase Purnama 1; B2 = Fase Baru 3; $\mathrm{P} 3=$ Fase Purnama 3; B3 = Fase Baru 4; P4 =Fase Purnama 4
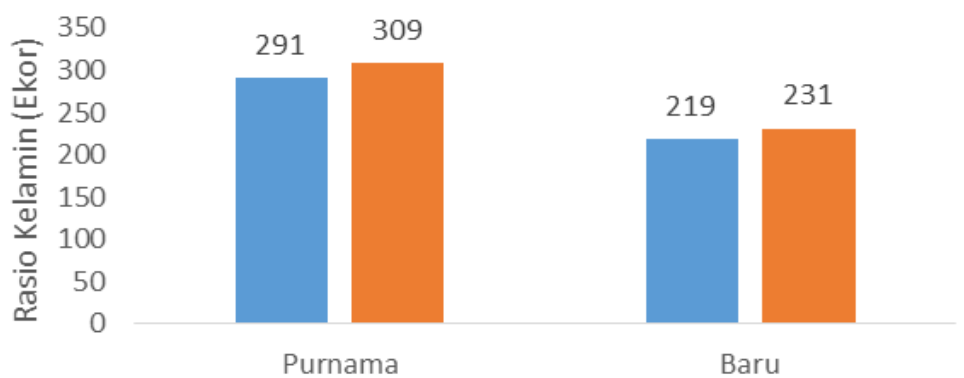

Fase Bulan

- Jantan Betina

Gambar 2. Nisbah Kelamin Rajungan di Perairan Telukawur 
Tabel 2. Distribusi Berat Rajungan

\begin{tabular}{|c|c|c|c|c|c|c|c|c|c|}
\hline \multirow{3}{*}{ No } & \multirow{3}{*}{ Interval (gram) } & \multirow{3}{*}{ Nilai Tengah } & \multicolumn{7}{|c|}{ Frekuensi Sebaran Berat Rajungan } \\
\hline & & & \multirow{2}{*}{$\begin{array}{c}\text { Oktober } \\
\text { P1 }\end{array}$} & \multicolumn{2}{|c|}{ November } & \multicolumn{2}{|c|}{ Desember } & \multicolumn{2}{|c|}{ Januari } \\
\hline & & & & $\mathrm{B} 1$ & $\mathrm{P} 2$ & B2 & P3 & B3 & $\mathrm{P} 4$ \\
\hline 1 & $56-82$ & 69 & 20 & 16 & 30 & 16 & 8 & 12 & 7 \\
\hline 2 & $82-108$ & 95 & 24 & 24 & 42 & 27 & 23 & 22 & 18 \\
\hline 3 & $108-134$ & 121 & 19 & 27 & 23 & 36 & 25 & 34 & 38 \\
\hline 4 & 134-161 & 148 & 24 & 19 & 15 & 36 & 22 & 30 & 37 \\
\hline 5 & $161-187$ & 174 & 24 & 22 & 13 & 16 & 27 & 21 & 22 \\
\hline 6 & $187-214$ & 201 & 19 & 16 & 15 & 8 & 20 & 12 & 14 \\
\hline 7 & $214-240$ & 227 & 11 & 16 & 5 & 8 & 10 & 8 & 8 \\
\hline 8 & $240-267$ & 253 & 7 & 5 & 3 & 0 & 10 & 5 & 4 \\
\hline 9 & $267-293$ & 280 & 2 & 3 & 3 & 2 & 1 & 4 & 1 \\
\hline 10 & 293-319 & 306 & 0 & 1 & 1 & 0 & 4 & 1 & 1 \\
\hline 11 & $319-346$ & 333 & 0 & 1 & 0 & 1 & 0 & 1 & 0 \\
\hline \multirow{2}{*}{\multicolumn{3}{|c|}{ Total }} & 150 & \multicolumn{2}{|c|}{300} & \multicolumn{2}{|c|}{300} & \multicolumn{2}{|c|}{300} \\
\hline & & & & & & 050 & & & \\
\hline
\end{tabular}

Keterangan : P1 = Fase Purnama 1; B1= Fase Baru 1; P2 = Fase Purnama 1; B2 = Fase Baru 3; P3 = Fase Purnama 3; B3 = Fase Baru 4; P4 =Fase Purnama 4

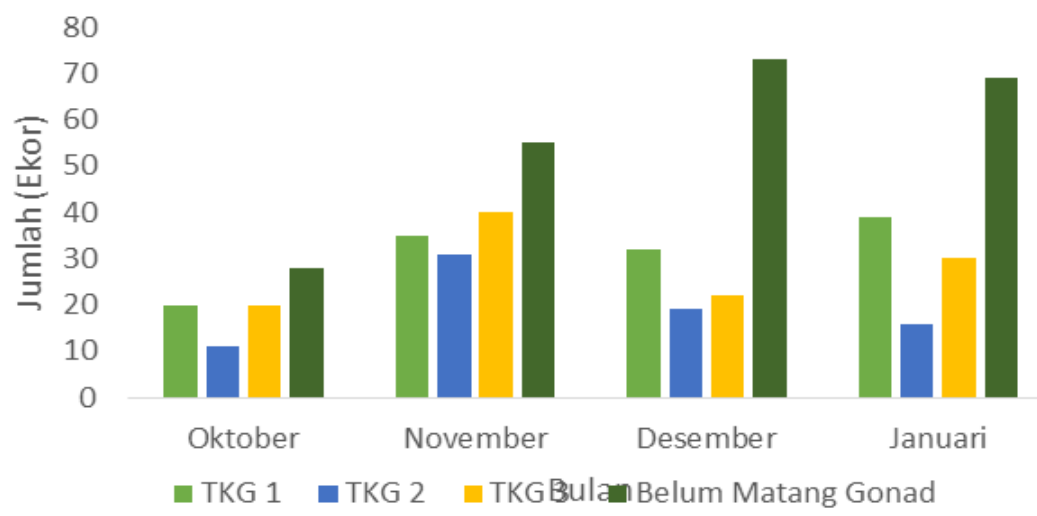

Gambar 3. Distribusi Tingkat Kematangan Gonad Rajungan di Perairan Teluk Awur

\section{Hubungan Panjang Berat}

Analisis hubungan panjang dan berat rajungan digunakan data panjang karapas rajungan dan berat rajungan untuk melihat pola pertumbuhan rajungan. Hubungan panjang berat juga dapat digunakan untuk menduga stok dalam satu biomassa, sebagai indikator kondisi dan pola pertumbuhan satu species, dan beberapa aspek lain dari dinamika populasi ikan maupun crustacea. Berdasarkan analisis hubungan panjang karapas dan berat rajungan didapatkan hasil bulan baru dan bula purnama nilai $b<3$, diketahui bahwa pola pertumbuhan menunjukkan allometrik negatif. Hasil ini menggambarkan bahwa pertumbuhan panjang karapas rajungan lebih dominan dibandingkan dengan pertumbuhan bobot tubuhnya.

Penentuan parameter pertumbuhan Von Bertalanffy berupa nilai $L \infty$ atau panjang infinitif dan koefisien pertumbuhan telah dilakukan dengan menggunakan Software FISAT II. Melalui penggunaan analisis ELEFAN I dari FISAT II dapat diketahui bahwa hasil penelitian didapatkan $L^{\infty}$ sebesar $8,61 \mathrm{~cm}$ dengan koefisien pertumbuhan $(K)$ sebesar 0,6 per tahun dan $t_{0}-0,80$. Nilai $L_{\infty}$ menunjukkan bahwa ukuran maksimal rajungan yang dapat dicapai sepanjang hidup alaminya yaitu sebesar $8,61 \mathrm{~cm}$. Nilai $\mathrm{K}$ menunjukkan kecepatan pertumbuhan untuk mencapai ukuran maksimal. Semakin besar nilai $\mathrm{K}$ maka semakin cepat pertumbuhan rajungan untuk mencapai ukuran maksimalnya. $\mathrm{t}_{0}$ merupakan umur teoritis pada saat panjang sama dengan 0 . 


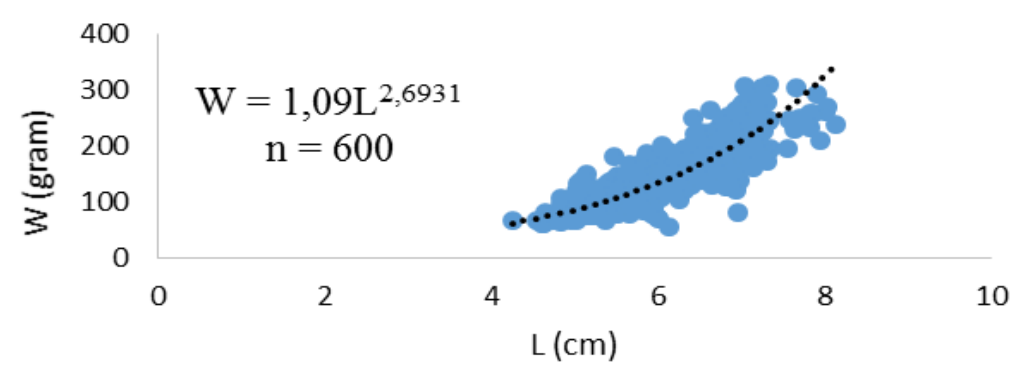

Gambar 4. Grafik Hubungan Panjang dan Berat pada bulan Purnama

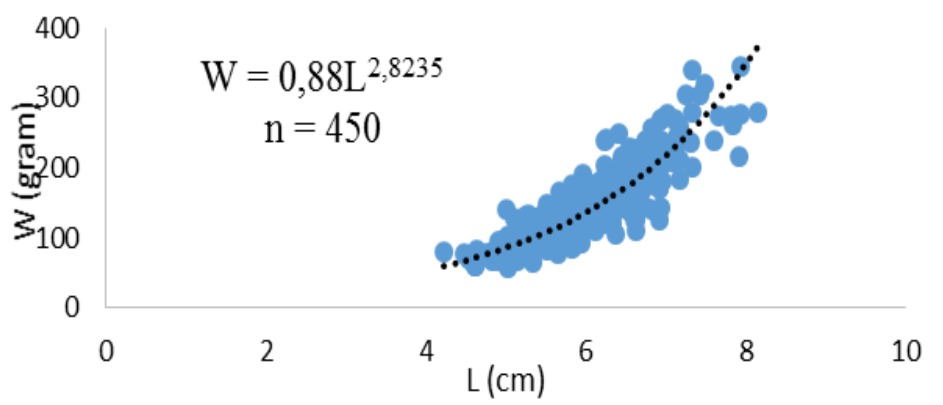

Gambar 5. Grafik Hubungan Panjang dan Berat pada bulan Baru

\section{KESIMPULAN}

Distribusi Ukuran Rajungan terbanyak di Perairan Telukawur yaitu berkisar 12,81-13,37 cm dan distribusi berat terbanyak berkisar 82-134 gram. Pola pertumbuhan rajungan di Perairan Teluk Awur adalah Allometrik Negatif dengan Faktor Kondisi 101,2693 pada bulan baru dan 101,43613 pada bulan purnama. Tingkat Pertumbuhan di Perairan Teluk Awur adalah L $\infty$ sebesar $8,61 \mathrm{~cm}$ dengan koefisien pertumbuhan $(\mathrm{K})$ sebesar 0,6 per tahun dan $\mathrm{t}_{0}-0,80$.

\section{DAFTAR PUSTAKA}

Irawan, H. 2015. Studi Pengaruh Siklus Bulan Terhadap Hasil Tangkapan Rajungan (Portunus pelagicus) di Perairan Teluk Banten, Serang. Universitas Terbuka. Jakarta. $181 \mathrm{hlm}$.

Kunsook, C., Gajaseni, N. \& Paphavasit, N. 2014. A stock assessment of the blue swimming crab Portunus pelagicus (Linnaeus, 1758) for sustainable management in Kung Krabean Bay, Gulf of Thailand. Tropical Life Sciences Research 25(1):41-59.

Mawaluddin, Haili \& Diyah, R.P. 2016. Komposisi Ukuran Kepiting Rajungan (Portunus pelagicus) Berdasarkan fase Bulan di Perairan Lakara, Konawe Selatan, Sulawesi Tenggara. Jurnal Manajemen Sumber Daya Perairan.1(3):299-310.

PERMEN KKP RI. 2015. Nomor 01/PERMEN-KP/2015 tentang Penangkapan Lobester (Panulirus spp), Kepiting (Scylla spp), dan Rajungan (Portunus pelagicus spp)

Rypel, A.L. \& Richter, T.J. 2008. Emperical percentile standard weight equation for the Blacktail Redhorse. North American Journal of Fisheries Management, 28:1843-1846

Sukamaran, K.K., Telang, K.Y. \& Thipeswamy, D. 1986. On The Fishery and Biology of Crab Portunus sanguinolentus (Herbst) Along the South Canara Coast. Indian Journal Fisheries. 33(2):188-200

Sunarto. 2012. Karakteristik Biologi Rajungan (Portunus pelagicus) di Perairan Laut Kabupaten Brebes. Program Studi IImu Kelautan, Institut Pertanian Bogor. 210 hlm. 